\title{
Relief from glucose-induced over-stimulation sensitizes the adenylate cyclase-cAMP system of rat pancreatic islets
}

\author{
A Björklund ${ }^{1}$ and V E Grill ${ }^{1,2}$ \\ ${ }^{1}$ Endocrine and Diabetes Unit, Department of Molecular Medicine, Karolinska Hospital, Karolinska Institute, S-171 76 Stockholm, Sweden \\ ${ }^{2}$ Endocrine Unit, Department of Medicine, University of Trondheim, N-7006 Trondheim, Norway \\ (Requests for offprints should be addressed to A Björklund, Endocrine Lab L6B:01, Karolinska Hospital, S-171 76, Stockholm, Sweden; \\ Email: anneli.bjorklund@molmed.ki.se)
}

\begin{abstract}
Hyperglycemia impairs $\beta$-cell function. This effect is partly exerted by $\beta$-cell over-stimulation by mechanisms that are not completely clarified. We have presently investigated whether over-stimulation alters the responsiveness of the islet adenylate cyclase-cAMP system. Effects of over-stimulation were assessed from comparisons in rat pancreatic islets after stimulation by culture for $22 \mathrm{~h}$ with high $(27 \mathrm{mM})$ glucose or after the additional presence of diazoxide which reversibly blocks secretion. Islet ATP levels were similar under both conditions. Forskolin increased islet cAMP levels dose-dependently after culture under both conditions; however, the cAMP responses to forskolin were enhanced by the previous co-presence of diazoxide: by 354, 183 and $168 \%$ respectively in the presence of $0 \cdot 1,1 \cdot 0$ and $25 \mu \mathrm{M}$ forskolin $(P<0 \cdot 05)$ or less for the effect of diazoxide. Enhancement was not diminished by $\mathrm{Ca}^{2+}$ omission during final incubations, nor by
\end{abstract}

blocking Gi proteins with pertussis toxin $(0 \cdot 1 \mu \mathrm{g} / \mathrm{ml})$. Enhancement was dependent on the glucose concentration during culture, i.e. co-culture with diazoxide at a non-stimulatory concentration of glucose $(6.0 \mathrm{mM})$ failed to affect the subsequent cAMP response to forskolin. Acute administration of glucose $(16.7 \mathrm{mM})$ failed to increase islet cAMP content after culture at high glucose only, whereas a modest (about 20\%) but significant stimulation was seen after co-culture with diazoxide. Co-culture with diazoxide left-shifted the insulin dose-response to a cAMP analogue 5,6-dichloro-1- $\beta$-Dribofuranosyl-benzimidazole- $3^{\prime}, 5^{\prime}$-cyclic monophosphorothioate. We conclude that over-stimulation importantly modifies the generation of cAMP, and also affects the insulin-releasing effect of the cyclic nucleotide.

Journal of Endocrinology (2000) 166, 537-544

\section{Introduction}

A diabetic state impairs $\beta$-cell function both in animals (Leahy et al. 1992) and in man (Yki-Järvinen 1992). Both hyperglycemia (Leahy et al. 1992, Yki-Järvinen 1992) and elevated free fatty acids (Sako \& Grill 1990a, Zhou \& Grill 1994) are involved in this process. One effect of hyperglycemia is a rapidly (within $24 \mathrm{~h}$ ) induced $\beta$-cell insensitivity to glucose. This effect of glucose is indirect. It can thus be protected against by inhibiting the insulinreleasing effect of glucose during hyperglycemia (Sako \& Grill 1990b). Such inhibition can be achieved with diazoxide. Diazoxide antagonizes the closing effect of glucose on ATP-dependent potassium channels (Trube et al. 1986), thereby inhibiting glucose-induced insulin secretion and simultaneously protecting against $\beta$-cell insensitivity (Sako \& Grill 1990b, Björklund \& Grill 1993). Over-stimulation is likely to be important in human diabetes, since ' $\beta$-cell rest' is beneficial in patients with type 1 diabetes with residual $\beta$-cell function (Björk et al. 1996, DCCT Study 1998) and in patients with overt type 2 diabetes (Greenwood et al. 1976, Garvey et al. 1985, Hollenbeck \& Reaven 1987, Yki-Järvinen et al. 1988).

It is not known to what extent over-stimulation affects different second messenger systems of the $\beta$-cell. In this study we have used diazoxide as a probe to examine the effects of over-stimulation on the adenylate cyclase-cAMP system. Increased knowledge of the function of this system in $\beta$-cells during high glucose conditions could be important clinically, since cAMP-raising agents, such as glucagon-like peptide 1 (GLP-1), are currently being tested for insulin-releasing potency in type 2 diabetic patients (Holst 1996). Our experimental design was to induce a state of relative over-stimulation by culturing islets at a high glucose concentration (Björklund \& Grill 1993, Björklund et al. 1997) and then to compare the functioning of the islet adenylate-cAMP system with that after co-culture with diazoxide. Specifically, the aims of the present study were (1) to test for effects of overstimulation on cAMP responses to forskolin, a potent stimulator of adenylate cyclase, (2) to test for effect of 
over-stimulation on a cAMP response to glucose and (3) to assess whether the insulin response to cAMP or a cAMP analogue is affected by over-stimulation.

\section{Materials and Methods}

\section{Animals}

Male Sprague-Dawley rats were obtained from B\&K Universal AB, Sollentuna, Sweden. At the time of experiments they weighed between 220 and $420 \mathrm{~g}$. All rats had free access to tap water and a standard pelleted diet (Rat and Mouse Standard Diet; B\&K Universal AB). The pellets contained, on a weight basis, $60 \cdot 3 \%$ carbohydrate, $20 \%$ protein, $4 \cdot 4 \%$ fat, $3 \cdot 3 \%$ supplements (vitamins and minerals), 3\% water and $4 \cdot 1 \%$ ashes. A $12-\mathrm{h}$ light:12-h darkness cycle (0600-1800 h) was enforced. The protocols used were approved by the Stockholm Ethics Committee for Animal Experiments.

\section{Materials}

Forskolin (dissolved in dimethyl sulfoxide) was from Sigma Chemical Co., St Louis, MO, USA, (Sp)5,6-dichloro$1-\beta$-D-ribofuranosyl-benzimidazole- $3^{\prime}, 5^{\prime}$-cyclic monophosphorothioate (cBIMPS) from Biolog Life Science Institute, Bremen, Germany, and diazoxide (Hyperstat) from Schering-Plough, Labo N.V., Heist-op-den-Berg, Belgium. Bovine serum albumin, fraction V (BSA) and pertussis toxin were obtained from Sigma.

\section{Isolation and culture of islets}

Pancreatic islets were isolated by digestion with collagenase (Boehringer-Mannheim, Mannheim, Germany) as described (Lacy \& Kostianovsky 1967). Digestion and sedimentation of islets were carried out in Hanks' medium containing $5.5 \mathrm{mM}$ glucose. Islets were then selected under a stereo microscope and transferred to Petri dishes (Sterilin, Teddington, Middx, UK). The islets were cultured for $20-22 \mathrm{~h}$ at $37^{\circ} \mathrm{C}$, in a gas phase of $5 \% \mathrm{CO}_{2}$ in air. Each dish contained $4.5 \mathrm{ml}$ RPMI 1640 (Statens veterinär medicinska anstalt, Uppsala, Sweden) with $27 \mathrm{mM}$ glucose or (in some experiments) $6 \mathrm{mM}$ glucose and $10 \%$ heat inactivated newborn calf serum (Sigma). The concentration of diazoxide, when present, was $325 \mu \mathrm{M}$. This concentration was chosen so as to provide at least $85 \%$ inhibition of glucose-induced insulin secretion (Björklund \& Grill 1993, Björklund et al. 1997).

\section{Measurements of cAMP}

Islets cultured as above were placed in batches of three into 'baskets' as previously described (Grill et al. 1977). The 'baskets' were prepared by cutting microcentrifu- gation plastic tubes (Beckman Ultra-Micro System, Spinco (Labora, Stockholm, Sweden)). The hollow cylinders thus obtained were capped with nylon gauze $\left(70\right.$ threads $/ \mathrm{cm}^{2}$ gauze, $36 \%$ open space). For preincubations, 'baskets' were immersed $0.5 \mathrm{~cm}$ in a Petri dish containing Krebs-Ringer bicarbonate (KRB) buffer (Cohen 1957) with 0.05\% BSA and $3.3 \mathrm{mM}$ glucose for a period of $30 \mathrm{~min}$ at $37^{\circ} \mathrm{C}$. Final incubations were started by transferring each 'basket' to a test tube with $300 \mu \mathrm{l} \mathrm{KRB}$ which contained $3.3 \mathrm{mM}$ glucose, $16.7 \mathrm{mM}$ glucose or $3.3 \mathrm{mM}$ glucose together with a forskolin concentration which was varied as specified below. Incubations were carried out for 5 or $15 \mathrm{~min}$ in a shaking water bath at $37^{\circ} \mathrm{C}$. Three to four 'baskets' were run for each experimental condition. To extract cAMP these final incubations were terminated by transferring 'baskets' into new tubes containing $200 \mu \mathrm{l} 50 \mathrm{mM}$ sodium acetate buffer. The 'baskets' were kept at $90-100{ }^{\circ} \mathrm{C}$ in the sodium acetate-containing tubes for $5 \mathrm{~min}$. The remaining KRB media of the 15-min incubations were saved for later determinations of insulin.

Islet contents of cAMP were determined in $0.15 \mathrm{ml}$ of boiled islet extracts using a kit (Amersham International plc, Amersham, Bucks, UK) in which acetylation was performed with acetic anhydride and triethylamine in volumes of 1:2 before adding $\left[{ }^{125} \mathrm{I}\right]$ cAMP and antiserum. The antibody-bound fraction was separated by centrifugation and counted in a gamma scintillation counter. The sensitivity of the assay was $1.0 \mathrm{fmol}$ and the range of concentrations assayable from the standard curve was 2-128 fmol/tube. The intra-assay coefficient of variation (C.V.) was $4-14 \%$ and the interassay C.V. was $5 \cdot 4-7 \cdot 0 \%$.

\section{Insulin release}

Following culture, islets were preincubated in $5 \mathrm{ml} \mathrm{KRB}$ (Cohen 1957) medium containing $10 \mathrm{mM}$ Hepes, 0.2\% BSA and $3.3 \mathrm{mM}$ glucose for $30 \mathrm{~min}$ at $37^{\circ} \mathrm{C}$. Islets were then transferred to tubes containing $300 \mu \mathrm{KRB}$ with additions dictated by each protocol. (When $\mathrm{Ca}^{2+}$ was omitted, $\mathrm{CaCl}_{2}$ was substituted with $\mathrm{NaCl}$ in an equimolar concentration.) Three to four tubes with three islets each were run for each experimental condition. Final incubations were carried out for 15 or $60 \mathrm{~min}$ at $37^{\circ} \mathrm{C}$ in a shaking water bath. At the end of incubations a sample of the medium was secured for insulin assay. Immunoreactive insulin was measured using rat insulin as standard and insulin antibodies which had been raised in our laboratory against porcine insulin. Bound and free insulin were separated after charcoal addition (Herbert et al. 1965).

\section{ATP}

ATP was measured by the firefly lantern luciferase method (Idahl 1979). After culture, batches of five islets were put into Beckman tubes containing an $\mathrm{NaOH}$ solution $(0 \cdot 04 \mathrm{M} \mathrm{NaOH}, 2 \mathrm{mM}$ EDTA) then frozen immediately 

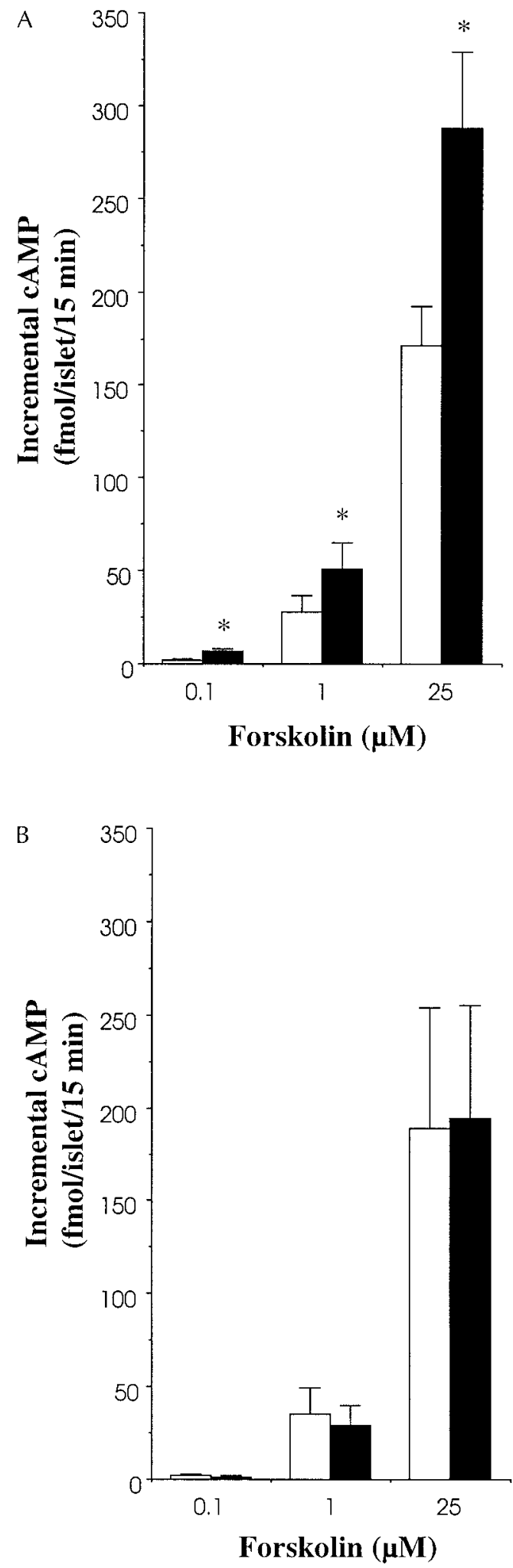

www.endocrinology.org on a mixture of ethanol/dry ice and stored at $-70{ }^{\circ} \mathrm{C}$. A $10^{-5} \mathrm{M}$ solution of ATP was prepared in Hepes buffer containing $25 \mathrm{mM}$ Hepes, $10 \mathrm{mM} \mathrm{MgSO}, 2 \mathrm{mM}$ EDTA, $1 \mathrm{mg} / \mathrm{ml} \mathrm{BSA}, \mathrm{pH}=7 \cdot 5$ and stored at $-70{ }^{\circ} \mathrm{C}$. From this stock solution, standard solutions $(2,1,0.5,0.25$ and $0.125 \mathrm{pmol}$ ATP $/ 20 \mu \mathrm{l}$ ) in Hepes buffer were prepared shortly before they were required. Before assay, islets were homogenized and incubated at $60{ }^{\circ} \mathrm{C}$ in a waterbath for $10 \mathrm{~min}$. The islet extracts were mixed with Hepes buffer containing luciferin, and luciferase (kindly provided by Professor Hans Löw) was added. Standard and blanks were treated identically to samples. Duplicate measurements were made from each batch of islets. Luminiscence was measured in a Packard scintillation counter.

\section{Expression of results}

Results are expressed as means \pm S.E.M. Significance testing was performed using Student's $t$-test for unpaired and paired data as appropriate and indicated in Tables, Figures and text. A $P$ value $<0.05$ was considered significant.

\section{Results}

\section{Islet cAMP contents under basal conditions}

Contents of cAMP during non-stimulatory conditions (i.e. in the presence of $3.3 \mathrm{mM}$ glucose) were assessed by pooling data from 42 experiments (some of which were used in other experiments not related to this study). Islets cultured without diazoxide contained $12.3 \pm 0.7 \mathrm{pmol} /$ islet and islets cultured with diazoxide $12 \cdot 8 \pm 0 \cdot 7 \mathrm{pmol} /$ islet $(P>0 \cdot 20)$. Thus, previous use of diazoxide did not alter cAMP contents in rat islets during non-stimulatory conditions.

\section{Effects of 0.1-25 $\mu M$ forskolin on islet cAMP}

In islets pre-cultured with $27 \mathrm{mM}$ glucose alone, forskolin increased cAMP by $2 \cdot 0 \pm 1,28 \cdot 0 \pm 9$ and $171 \pm 21 \mathrm{fmol} /$ islet at forskolin concentrations of $0 \cdot 1,1 \cdot 0$ and $25 \mu \mathrm{M}$ (Fig. 1A). These effects of forskolin were obtained in the co-presence of $3.3 \mathrm{mM}$ glucose.

The stimulatory effects of forskolin were significantly increased in diazoxide-precultured islets. The cAMP responses were thus $7 \cdot 1 \pm 0 \cdot 8, \quad 51 \pm 14$ and $288 \pm$ $41 \mathrm{fmol} /$ islet respectively, $P<0 \cdot 025$ or less for the effects of diazoxide vs $27 \mathrm{mM}$ glucose alone (Fig. 1A). The

Figure 1 Effects of forskolin on cAMP levels. Islets were pre-cultured for 20-22 h in (A) $27 \mathrm{mM}$ glucose or (B) $6.0 \mathrm{mM}$ glucose in the presence (solid bars) or absence (open bars) of $325 \mu \mathrm{M}$ diazoxide. Data are means \pm S.E.M. for (A) six or (B) four experiments. ${ }^{\star} P<0.025$ or less for effect of diazoxide. 
Table 1 Effects of calcium omission on islet cAMP. Islets were cultured for 20-22 h in $27 \mathrm{mM}$ glucose in the absence or presence of $325 \mu \mathrm{M}$ diazoxide. $\mathrm{Ca}^{2+}$ was omitted during 30-min preincubations and 15-min final incubations. Data are means \pm S.E.M. fmol/islet per 15 min; there were seven experiments

Final incubations

\begin{tabular}{|c|c|c|c|c|}
\hline $\begin{array}{l}\text { Glucose } \\
(\mathrm{mM})\end{array}$ & $\begin{array}{l}\text { Forskolin } \\
(\mu \mathrm{M})\end{array}$ & $\begin{array}{l}\text { Calcium } \\
\text { added } \\
(2.5 \mathrm{mM})\end{array}$ & $\begin{array}{l}\text { Glucose } \\
(27 \mathrm{mM})\end{array}$ & $\begin{array}{l}\text { Glucose } \\
(27 \mathrm{mM}) \text { and } \\
\text { diazoxide } \\
(325 \mu \mathrm{M})\end{array}$ \\
\hline $3 \cdot 3$ & - & + & $13 \cdot 0 \pm 1 \cdot 1$ & $13 \cdot 9 \pm 2 \cdot 0$ \\
\hline $3 \cdot 3$ & 25 & + & $227 \pm 43$ & $430 \pm 79^{*}$ \\
\hline $3 \cdot 3$ & - & - & $15 \cdot 8 \pm 1 \cdot 8$ & $13 \cdot 9 \pm 2 \cdot 0$ \\
\hline $3 \cdot 3$ & 25 & - & $293 \pm 47$ & $487 \pm 88^{*}$ \\
\hline
\end{tabular}

${ }^{*} P<0 \cdot 025$ for effect of diazoxide.

amplifying effect of previous diazoxide amounted to 354, 183 and $168 \%$ of the cAMP responses in islets not pretreated with diazoxide.

It was important to determine whether the effects of diazoxide were due to inhibition of glucose stimulation rather than to an effect of the drug per se. To this end, islets were cultured for $20 \mathrm{~h}$ at a non-stimulatory concentration of glucose $(6.0 \mathrm{mM})$ in the absence or presence of diazoxide. During these conditions diazoxide pretreatment did not affect forskolin-induced increases in cAMP (Fig. 1B).

Effects of calcium omission on the forskolin-induced rise in islet cAMP

Forskolin is known to directly stimulate adenylate cyclase; however, such stimulation could possibly be potentiated by a calcium-dependent and calmodulin-mediated enhancement of adenylate cyclase activity (Sharp 1979, Valverde et al. 1979). In the present work, calcium omission during preincubation and final incubations failed to inhibit the rise in cAMP evoked by $25 \mu \mathrm{M}$ forskolin; instead calcium omission tended to increase cAMP levels (Table 1). Importantly, calcium omission failed to affect the enhancement by diazoxide of forskolin-stimulated cAMP contents. Similar results were obtained when final incubations contained a low concentration $(0 \cdot 1 \mu \mathrm{M})$ of forskolin ( $n=6$, results not shown).

\section{Effect of pertussis toxin on the forskolin-induced rise in cAMP}

Specific G proteins (Gi) inhibit adenylate cyclase activity and this effect is blocked by pertussis toxin. We used pertussis toxin $(0 \cdot 1 \mu \mathrm{g} / \mathrm{ml})$ to investigate whether increased $\mathrm{Gi}$ activity mediates the over-stimulation effects on cAMP. Such a notion would be supported if pertussis toxin abolished or attenuated the difference in forskolininduced cAMP between non-diazoxide- and diazoxide-

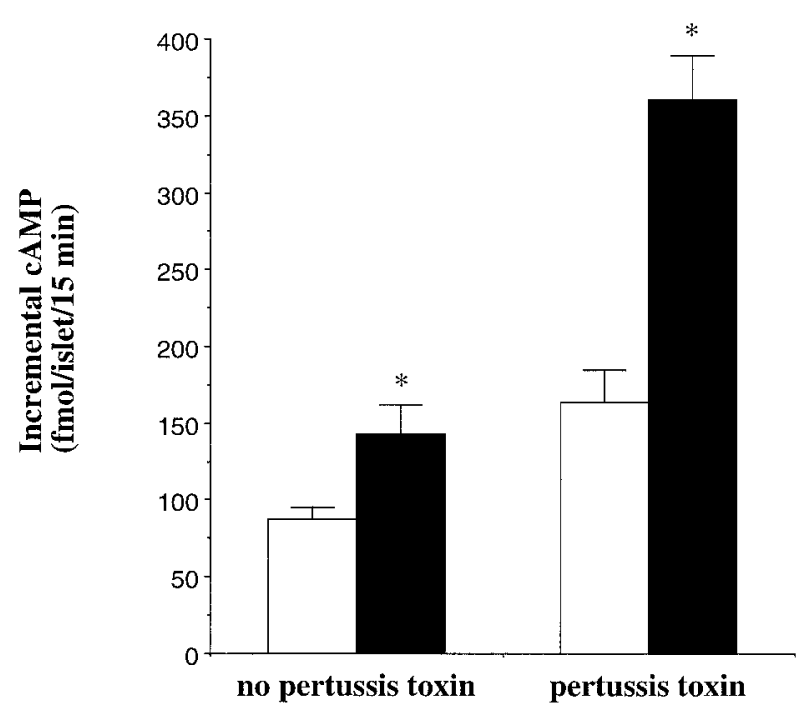

Figure 2 Effect of pertussis toxin $(0 \cdot 1 \mu \mathrm{g} / \mathrm{ml})$ during preincubation and final incubations for $15 \mathrm{~min}$ on the forskolin-induced cAMP response. The concentration of forskolin was $25 \mu \mathrm{M}$ in the presence of $3.3 \mathrm{mM}$ glucose. Islets were pre-cultured for $20-22 \mathrm{~h}$ in $27 \mathrm{mM}$ glucose in the presence (solid bars) or absence (open bars) of $325 \mu \mathrm{M}$ diazoxide. Data are means \pm S.E.M. of three experiments. ${ }^{*} P<0.05$ or less for effect of diazoxide.

pretreated islets. Such findings were not obtained; in contrast, pertussis toxin tended to increase the difference in forskolin-induced cAMP between non-diazoxide- and diazoxide-pretreated islets. The effect of diazoxide was thus an increase from 163 to $360 \mathrm{fmol} /$ islet $(2 \cdot 2$-fold $)$ in islets treated with pertussis toxin as compared with an increase from 87 to $143 \mathrm{fmol} /$ islet $(1 \cdot 6$-fold) in islets not treated with the toxin (Fig. 2).

\section{Effects of $11 \mathrm{mM}$ glucose on the forskolin-induced rise in} cAMP

Interactions between forskolin and glucose on cAMP levels were investigated by comparing the effects of $0 \cdot 1 \mu \mathrm{M}$ forskolin at a stimulatory and a non-stimulatory concentration of glucose (Table 2). Glucose (11 vs $3.3 \mathrm{mM}$ glucose, in combination with forskolin) failed to significantly affect cAMP contents. At both combinations of glucose and forskolin, the cAMP contents were lower in non-diazoxide- than in diazoxide-pretreated islets.

\section{Effects of $16.7 \mathrm{mM}$ glucose on islet cAMP}

Stimulation with $16.7 \mathrm{mM}$ glucose in the final incubations failed to induce an islet cAMP response in islets precultured at high glucose (Fig. 3). However, islets that had been cultured in the concomitant presence of diazoxide were responsive. In these islets, $16.7 \mathrm{mM}$ glucose 
Table 2 Effects of $11 \mathrm{mM}$ glucose on forskolin-induced rise in cAMP. Islets were cultured for $20-22 \mathrm{~h}$ in $27 \mathrm{mM}$ glucose in the absence or presence of $325 \mu \mathrm{M}$ diazoxide. Data are means \pm S.E.M. $\mathrm{fmol} /$ islet per $15 \mathrm{~min}$; there were eight experiments

Final incubations

\begin{tabular}{|c|c|c|c|}
\hline $\begin{array}{l}\text { Glucose } \\
(\mathrm{mM})\end{array}$ & $\begin{array}{l}\text { Forskolin } \\
(\mu \mathrm{M})\end{array}$ & $\begin{array}{l}\text { Glucose } \\
(27 \mathrm{mM})\end{array}$ & $\begin{array}{l}\text { Glucose } \\
(27 \mathrm{mM}) \text { and } \\
\text { diazoxide } \\
(325 \mu \mathrm{M})\end{array}$ \\
\hline $3 \cdot 3$ & - & $15 \cdot 4 \pm 0 \cdot 6$ & $16 \cdot 1 \pm 0 \cdot 5$ \\
\hline $3 \cdot 3$ & $0 \cdot 1$ & $19 \cdot 3 \pm 0 \cdot 9$ & $22 \cdot 9 \pm 1 \cdot 5^{*}$ \\
\hline 11 & - & $16 \cdot 0 \pm 0 \cdot 5$ & $17 \cdot 2 \pm 0 \cdot 7$ \\
\hline 11 & $0 \cdot 1$ & $20 \cdot 0 \pm 1 \cdot 3$ & $23 \cdot 7 \pm 1 \cdot 5^{*}$ \\
\hline
\end{tabular}

${ }^{*} P<0.025$ for effect of diazoxide.

increased cAMP levels modestly but significantly $(+21 \%$ after 5 - $\min$ and $+17 \%$ after 15 -min final incubations, $P<0 \cdot 05$, Fig. 3).

\section{ATP}

Because ATP is the substrate for adenylate cyclase we determined islet contents of ATP after culture with $27 \mathrm{mM}$ glucose without and with diazoxide. Previous diazoxide failed to affect islet contents of ATP $(12 \cdot 0 \pm 2 \cdot 6 \mathrm{pmol} /$ islet without and $11 \cdot 2 \pm 1 \cdot 4$ after culture with diazoxide, $n=4)$.

\section{Insulin responses to forskolin and to glucose}

At low $(3.3 \mathrm{mM})$ glucose, forskolin induced only modest insulin responses (Fig. 4A).

Forskolin-induced insulin responses were greatly potentiated by increasing the glucose concentration to $11 \mathrm{mM}$ (compare Fig. 4A and B). Enhancement by glucose was less marked in islets cultured without than in those cultured with diazoxide. The after-effect of diazoxide was further enhanced in final incubations performed for 60 compared with 15 min (compare Fig. 4B and $\mathrm{C}$ ). The difference was not due to an effect of diazoxide per se since previous diazoxide was without effect when the culture medium contained $6 \cdot 0$ rather than $27 \mathrm{mM}$ glucose (results not shown)

\section{Effect of 0.01-0.1 $\mathrm{mM}$ cBIMPS on insulin release}

In order to further evaluate the effects of cAMP on insulin secretion during conditions of over-stimulation, an analogue of cAMP (cBIMPS) was added to intact islets. This compound has shown increased lipophilicity compared with 8-(p-chlorophenylthio)-cAMP (Sandberg et al. 1991). It also potently and specifically activates cAMPdependent protein kinase, and is resistant to hydrolysis by

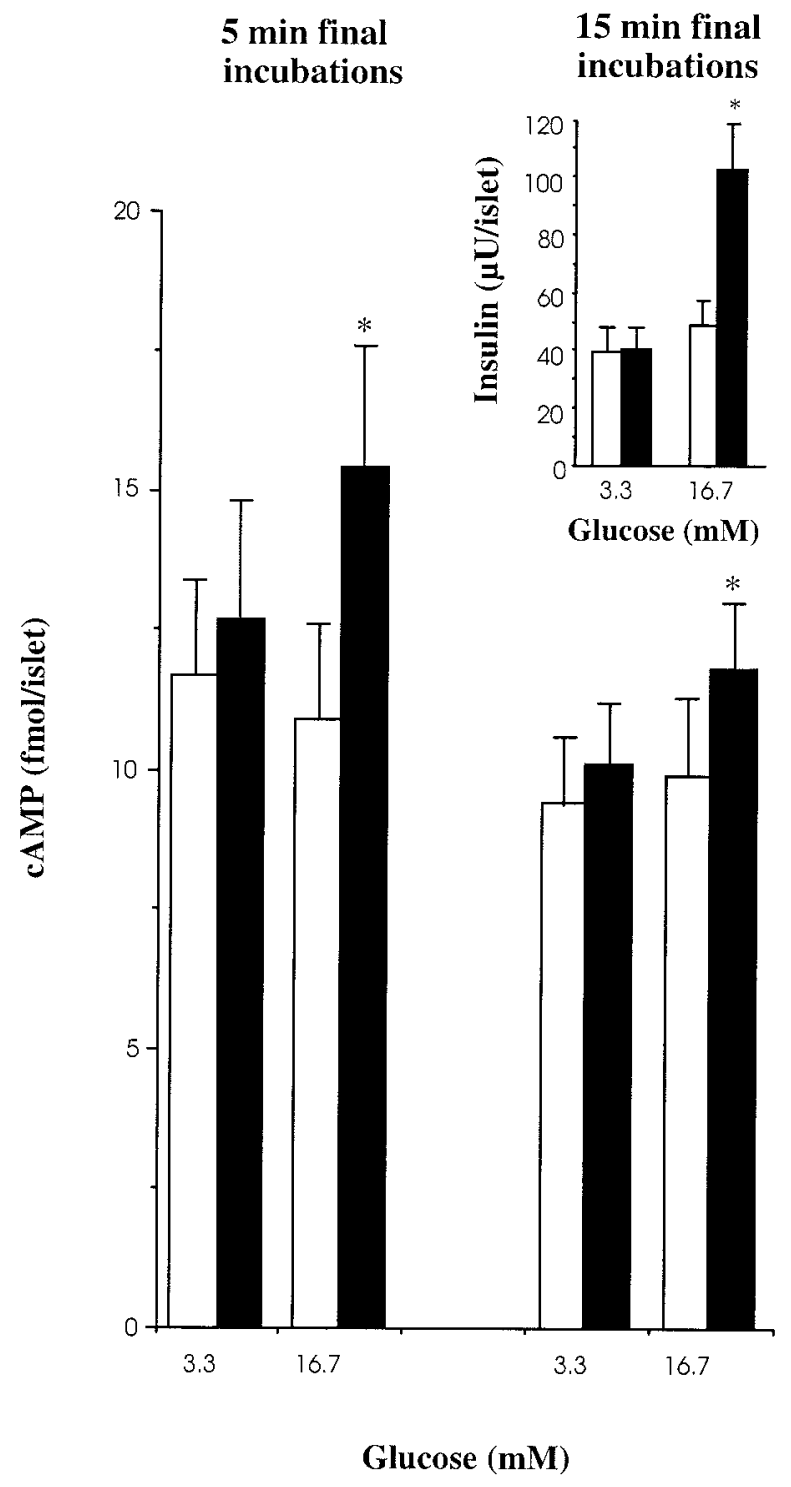

Figure 3 Effects of $16.7 \mathrm{mM}$ glucose on islet cAMP content and insulin release (insert). Islets were pre-cultured for $20-22 \mathrm{~h}$ in $27 \mathrm{mM}$ glucose in the presence (solid bars) or absence (open bars) of $325 \mu \mathrm{M}$ diazoxide. Data are means \pm S.E.M. of six or seven experiments. ${ }^{\star} P<0 \cdot 05$ or less for effect of glucose.

cyclic nucleotide phosphodiesterases (Sandberg et al. 1991). In non-diazoxide-treated islets, only the highest concentration $(0.1 \mathrm{mM})$ of cBIMPS (tested at $6.0 \mathrm{mM}$ glucose) increased insulin release (Fig. 5). After pretreatment with diazoxide the lower concentrations of 0.025 and $0.05 \mathrm{mM}$ cBIMPS were also stimulatory (Fig. 5, $P<0.025$ for effect of diazoxide pretreatment). With $0.1 \mathrm{mM}$ cBIMPS, insulin secretion in diazoxide-cultured islets was not significantly higher than from islets without diazoxide pretreatment $(P<0 \cdot 15$, Fig. 5$)$. 
A

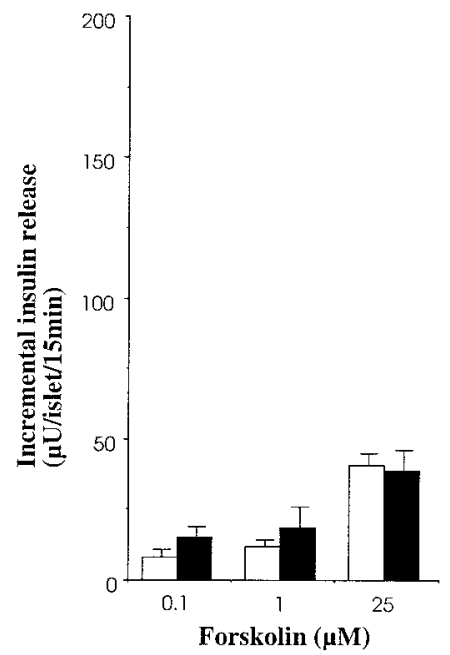

B

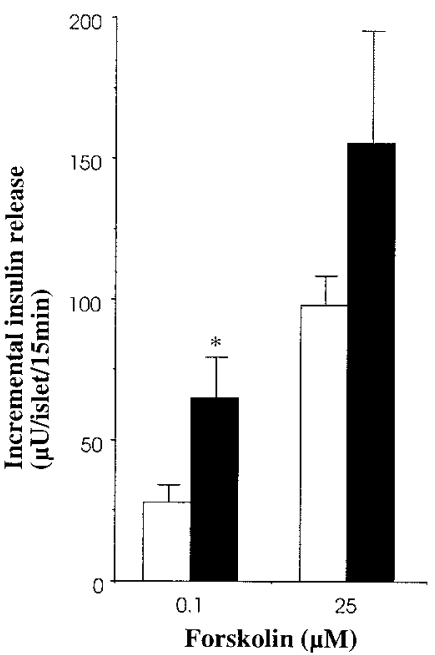

C

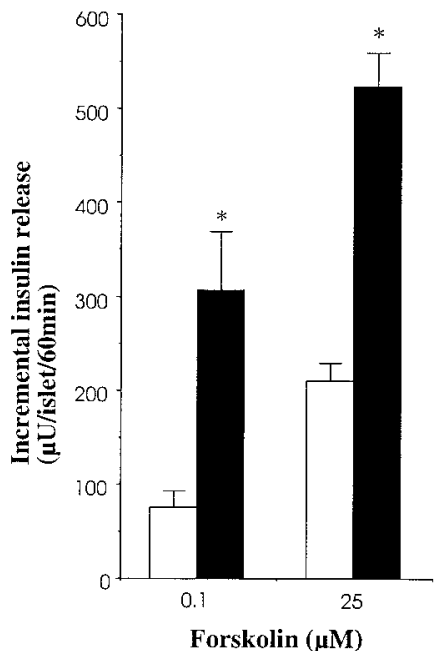

Figure 4 Forskolin-induced insulin release at (A) 3.3 or (B and C) $11 \mathrm{mM}$ glucose. (A and B) 15-min final incubation and (C) 60-min final incubation. Islets were pre-cultured for $20-22 \mathrm{~h}$ in $27 \mathrm{mM}$ glucose in the presence (solid bars) or absence (open bars) of $325 \mu \mathrm{M}$ diazoxide. Data are means \pm S.E.M. of six experiments. ${ }^{*} P<0 \cdot 05$ or less for effect of diazoxide.

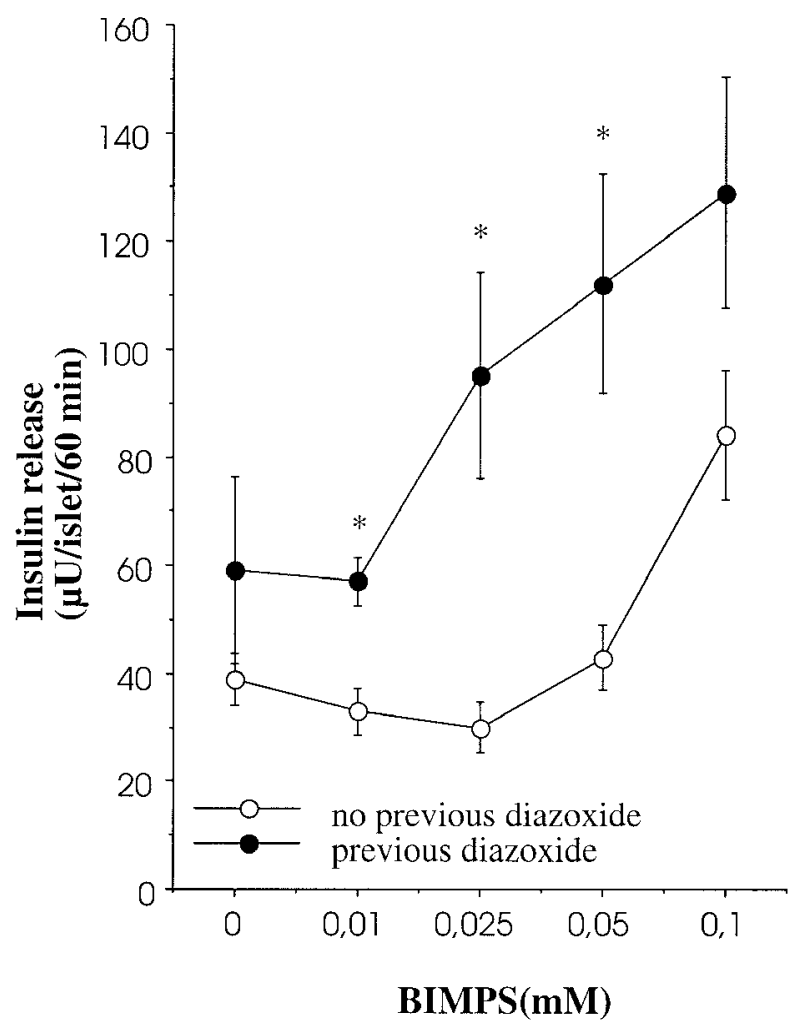

Figure 5 Effects of $0 \cdot 01-0 \cdot 1 \mathrm{mM}$ cBIMPS in intact islets. Islets were pre-cultured for $20-22 \mathrm{~h}$ in $27 \mathrm{mM}$ glucose in the presence () or absence $(\bigcirc)$ of $325 \mu \mathrm{M}$ diazoxide. Data are means \pm S.E.M. of seven experiments. ${ }^{\star} P<0 \cdot 05$ or less for effect of diazoxide.

\section{Discussion}

Our study demonstrates, for the first time, that overstimulation exerts several important effects on the adenylate cyclase-cAMP signal transduction pathway. These effects include, in intact islets, a decreased cAMP response to forskolin, a complete loss of a modest cAMP response to glucose and a right-shift of the insulin response to a cAMP analogue.

The dose-response experiments with forskolin demonstrate that diazoxide pretreatment augments the cAMP responses at all concentrations of forskolin. Since forskolin acts at the catalytic subunit of adenylate cyclase (Seamon \& Daly 1981) our findings indicate a basic (not receptorrelated) influence by over-stimulation on adenylate cyclase activity. This influence of over-stimulation seems not to be due to substrate (ATP) deficiency, since ATP contents were similar in diazoxide-pretreated and untreated islets. Furthermore, our results with pertussis toxin indicate that Gi proteins are not involved in the over-stimulation effect.

Our results also demonstrate a complete loss of a cAMP response to a high $(16.7 \mathrm{mM})$ glucose concentration. Such a response is known to be modest in freshly isolated islets of the rat and was also so in islets cultured in the presence of diazoxide. Loss of a cAMP response to glucose during culture was reported many years ago (Rabinovitch et al. 1978) and more recently confirmed (Laychock 1995). Our results with diazoxide offer over-stimulation as a possible explanation for the loss of a glucose-induced cAMP response after culture.

Our results do not support a role of $\mathrm{Ca}^{2+}$ fluxes behind the effects of diazoxide on the forskolin-induced cAMP 
response, since the enhancing effect of previous diazoxide was also upheld after $\mathrm{Ca}^{2+}$ omission. In this context, it is interesting that cAMP responses to forskolin were increased rather than decreased by $\mathrm{Ca}^{2+}$ omission. Such an enhancing effect could be secondary to activation of $\mathrm{Ca}^{2+}$-inhibitable isoforms of adenylate cyclase which have been demonstrated in $\beta$-cells (Leech 1999).

The dose-response to different concentrations of a potent (Laychock 1993) cAMP analogue (cBIMPS) suggests that relief from over-stimulation by previous diazoxide left-shifted the potency of cAMP to release insulin. This notion is compatible with the insulin data obtained with forskolin at $3.3 \mathrm{mM}$ glucose (Fig. 4A). However, at $11 \mathrm{mM}$ glucose, a high forskolin concentration $(25 \mu \mathrm{M})$ exerted a more marked insulin response in diazoxide-pretreated than in non-pretreated islets. Although the per cent increase due to diazoxide was smaller with 25 than with $0 \cdot 1 \mu \mathrm{M}$ forskolin, the last mentioned data nevertheless indicate an effect on maximal capacity for secretion. This could, in turn, be secondary to a well-documented twofold difference in islet insulin content (Björklund \& Grill 1993). It seems possible that relief from over-stimulation has two effects: one that leads by unknown mechanisms to a left-shift in potency of cAMP for insulin secretion, another that affects maximal capacity for secretion because of higher islet insulin content. Further studies are needed to assess the relative roles of these putative mechansims.

It is interesting to note that the adenylate cyclase stimulators glucagon and GLP-1 can induce insulin secretion in type 2 diabetic patients (Gutniak et al. 1992, Holst 1996, Nauck 1998) and that such stimulation is observed under conditions of over-stimulation and $\beta$-cell insensitivity to glucose (Castillo et al. 1996). Our finding that the potential for large cAMP responses at high concentrations of forskolin is retained after high glucose culture may offer a molecular basis for the potency of the cAMP-raising secretagogues when used in pharmacological concentrations.

In summary, our study has shown, for the first time, that 'resting' $\beta$-cells from intense and prolonged glucoseinduced stimulation enhance the adenylate cyclase-cAMP transduction pathway, both with regard to a cAMP response and to the effect of the second messenger on insulin secretion. The enhancing effect on forskolininduced cAMP responses is not dependent on $\mathrm{Ca}^{2+}$ inflow, nor on substrate (ATP) availability, nor on interactions with Gi proteins. As to insulin responses to cAMP, our results also indicate that enhancement is due, at least in part, to a left-shift in the dose-response for cAMP.

\section{Acknowledgements}

This study was supported by the Swedish Medical Research Council (Grant 04540), the Swedish Diabetes
Association, the Magnus Bergvall Foundation, the Novo-Nordic Insulin Foundation, the Swedish Society of Medicine, the Swedish Society for Medical Research and Funds from the Karolinska Institute. We are indebted to Ms Elvi Sandberg for help with the cAMP assay.

\section{References}

Björk E, Berne C, Kämpe O, Wibell L, Oskarsson P \& Karlsson FA 1996 Diazoxide treatment at onset preserves residual insulin secretion in adults with autoimmune diabetes. Diabetes $\mathbf{4 5}$ 1427-1430.

Björklund A \& Grill V 1993 B-cell insensitivity in vitro: reversal by diazoxide entails more than one event in stimulus-secretion coupling. Endocrinology 132 1319-1328.

Björklund A, Östenson C-G \& Grill V 1997 Defective insulin secretion in the GK rat is not linked to excessive B-cell stimulation. Pancreas 14 212-214.

Castillo MJ, Scheen AJ, Paolisso G \& Lefebvre PJ 1996 Exhaustion of blood glucose response and enhancement of insulin response after repeated glucagon injections in type-2 diabetes: potentiation by progressive hyperglycemia. Annales d'Endocrinologie $\mathbf{5 7}$ 395-402.

Cohen PP 1957 Methods for preparation and study of tissues: suspending media for animal tissues. In Manometric Techniques, pp 149-150. Eds WW Umbreit, RH Burris \& JF Stauffer. Minneapolis: Burgess Publishing Co.

DCCT Study 1998 Effect of intensive therapy on residual beta-cell function in patients with type 1 diabetes in the control and complications trial. Annals of Internal Medicine 128 517-523.

Garvey WT, Olefsky JM, Griffin J, Hamman RF \& Kolterman OG 1985 The effect of insulin treatment on insulin secretion and insulin action in type II diabetes mellitus. Diabetes 34 222-234.

Greenwood RH, Mahler RF \& Hales CN 1976 Improvement in insulin secretion in diabetes after diazoxide. Lancet i 444-447.

Grill V, Borglund E \& Cerasi E 1977 Cyclic AMP in rat pancreatic islets. Evidence for uniform labeling for precursor and product with $\left[{ }^{3} \mathrm{H}\right]$-adenine. Biochimica et Biophysica Acta 499 251-258.

Gutniak M, Orskov C, Holst JJ, Ahren B \& Efendic S 1992 Antidiabetogenic effect of glucagon-like peptide-1 (7-36) amide in normal subjects and patients with diabetes mellitus. New England Journal of Medicine 326 1316-1322.

Herbert V, Lau KS, Gottlieb CW \& Bleicher SJ 1965 Coated charcoal immunoassay of insulin. Journal of Clinical Endocrinology and Metabolism 25 1375-1384.

Hollenbeck CB \& Reaven GM 1987 Treatment of patients with noninsulin-dependent diabetes mellitus: diabetic control and insulin secretion and action after different treatment modalities. Diabetic Medicine 4 311-316.

Holst JJ 1996 GLP-1 in NIDDM. Diabetic Medicine 13 156-160.

Idahl A 1979 Assay of subpicomol amounts of phosphoenolpyruvate using the firefly luciferase system. In 'Proceedings 1978', International Symposium on Analytical Applications of Bioluminescense and Chemiluminescence, pp 401-410. Eds E Schram \& P Stanley. Westlake Village, CA: State Printing \& Publishing, Inc.

Lacy PE \& Kostianovsky M 1967 Method for the isolation of intact islets of Langerhans from the rat pancreas. Diabetes 16 35-39.

Laychock SG 1993 (Sp)5,6-dichloro-1- $\beta$-D-ribofuranosylbenzimidazole- $3^{\prime}, 5^{\prime}$-cyclic monophosphorothioate is a potent stimulus for insulin release. Endocrine Research 19 113-122.

Laychock SG 1995 Impaired cyclic AMP response to stimuli in glucose-desensitized rat pancreatic islets. Molecular and Cellular Endocrinology 113 19-28.

Leahy JL, Bonner-Weir S \& Weir GC 1992 B-cell dysfunction induced by chronic hyperglycemia. Diabetes Care 15 442-455. 
Leech CA, Castonguay MA \& Habener JF 1999 Expression of adenylyl cyclase subtypes in pancreatic $\beta$-cells. Biochemical and Biophysical Research Communications 254 703-706.

Nauck MA 1998 Glucagon-like peptide 1 (GLP-1): a potent gut hormone with a possible therapeutic perspective. Acta Diabetologica 35 117-129.

Rabinovitch A, Cuendet G, Sharp G, Renold A \& Mintz D 1978 Relation of insulin release to cyclic AMP content in rat pancreatic islets maintained in tissue culture. Diabetes 27 766-773.

Sako Y \& Grill V 1990a A 48 h lipid infusion in the rat timedependently inhibits glucose-induced insulin secretion and B-cell oxidation through a process likely coupled to fatty acid oxidation. Endocrinology 127 1580-1589.

Sako Y \& Grill V 1990b Coupling of B-cell desensitization by hyperglycemia to excessive stimulation and circulating insulin in glucose-infused rats. Diabetes 39 1580-1583.

Sandberg M, Butt E, Nolte C, Fischer L, Halbrügge M, Beltman J, Jahnsen T, Genieser H-G, Jastorff B \& Walter U 1991 Characterization of Sp-5,6-dichloro-1- $\beta$-D-ribofuranosyl-benzimidazole- $3^{\prime}, 5^{\prime}$ monophosphorothioate (Sp-5,6-DCl-cBIMPS) as a potent and specific activator of cyclic-AMP-dependent protein kinase in cell extracts and intact cells. Biochemical Journal 279 521-527.

Seamon K \& Daly JW 1981 Activation of adenylate cyclase by the diterpene forskolin does not require the guanine nucleotide regulatory protein. Journal of Biological Chemistry 256 9799-9801.
Sharp GW 1979 The adenylate cyclase-cyclic AMP system in islets of Langerhans and its role in the control of insulin release. Diabetologia $16287-296$.

Trube G, Rorsman P \& Shosaku O 1986 Opposite effects of tolbutamide and diazoxide on the ATP dependent $\mathrm{K}^{+}$channels in mouse pancreatic $\beta$-cells. Pflügers Archiv: European Journal of Physiology 407 493-499.

Valverde I, Vandermeers A, Anjaneyulu R \& Malaisse WJ 1979 Calmodulin activation of adenylate cyclase in pancreatic islets. Science 206 225-227.

Yki-Järvinen H 1992 Glucose toxicity. Endocrine Reviews 13 415-431.

Yki-Järvinen H, Nikkilä E, Helve E \& Taskinen MR 1988 Clinical benefits and mechanisms of a sustained response to intermittent insulin therapy in Type 2 diabetic patients with secondary drug failure. American Journal of Medicine 84 185-192.

Zhou Y-P \& Grill V 1994 Long term exposure of rat pancreatic islets to fatty acids inhibits glucose-induced insulin secretion and biosynthesis through a glucose fatty acid cycle. Journal of Clinical Investigation 93 870-876.

Received 17 February 2000

Accepted 10 May 2000 